\title{
Experimental Study of Spatial Cognition Capability Enhancement with Building Block Learning Contents for Disabled Children
}

\author{
Kohei Arai, Taiki Ishigaki \\ Graduate School of Science and Engineering \\ Saga University, Saga City, Japan
}

\author{
Mariko Oda \\ Hagoromo University of International Studies \\ Osaka, Japan
}

\begin{abstract}
In this research, we develop learning teaching materials using building blocks for children with disabilities, and verify learning effect. It is important to prepare input equipment according to children with disabilities and to prepare learning materials according to the ability you have learned. Therefore, this time we developed a teaching material using building blocks to improve spatial recognition capability using touch pad and tablet as input device. It is decided to measure the effect by comparing the scores learned by actually combining the input device and the learning material. Through experiments with participants of disabled children, it is found that the learning contents are effective and appropriate for improvement of their spatial recognition capability.
\end{abstract}

Keywords-Experiment; slope surfaces; interaction between two surfaces

\section{INTRODUCTION}

Children have acquired the ability to become the basis of learning from activities such as living activities and playing. However, some children have restricted activities due to obstacles, and they miss opportunities to learn. For example, in the study of building blocks for young children In the research of Ito - Takahashi, the child A performs the actions such as "loading", "breaking", "hitting", "arranging", which are basic motions for playing using building blocks Experienced. After winning acts to pile up, they repeatedly challenged play and confirmed play and experienced "interval", "width/depth/height", "center of gravity", "balance", etc.

It can be pointed out that child $\mathrm{A}$ is acquiring the concept of "plane" "solid" through building blocks [1]. However, some children who have disabilities use the real building blocks. It is difficult to learn. Children with severely overlapping obstacles have difficulty in displaying intention based on voice and behavior, and there are many passive learning that only learning is heard, learning is listening. In special support schools, various education is conducted according to the progress of each individual development and disability based on the guidelines for teaching special support schools [2]. The faculty prepares for the learning environment tailored to the student. ICT can be used effectively in order to teach instruction according to students. Therefore, in this research, we aim to improve the spatial recognition capability by using a learning environment that combines input equipment according to student's disability and learning materials using building blocks. Learning materials, by changing input devices, consider the teaching materials that can be used regardless of the degree of disability.

Development of learning support software with CG animations for intellectually disabled children is conducted [3]. Spatial comprehension exercise system with 3D CG of toy model for disable children is proposed and is well reported [4]. Also, learning content for improvement of spatial comprehension capability with 3D CG toy model for disable children is proposed [5].

In this research, we develop learning teaching materials using building blocks for children with disabilities, and verify learning effect. It is important to prepare input equipment according to children with disabilities and to prepare learning materials according to the ability you have learned. Therefore, this time we developed a teaching material using building blocks to improve spatial recognition capability using touch pad and tablet as input device. It is decided to measure the effect by comparing the scores learned by actually combining the input device and the learning material.

Research background is described in the next section followed by learning content creation. Then experiments with specific disabled children are described followed by conclusion with some discussions.

\section{RESEARCH BACKGROUND}

\section{A. Disabled Children}

A child with physical disability is a child with disabilities in motor function such as hands, feet, spine, etc. due to injury at birth or childbirth, or illness or accident at young age. The condition varies according to inconvenient parts and degrees. In the case where the exercise / motion of the right hand or right body only, or both feet, and even the whole body is inconvenient.

There is a match. In addition, the extent is also diverse, such as those who do not feel difficulty in everyday life, those who need prosthetic gear such as pine needle stick and wheel chair, and even those who need assistance for many activities [6].

Involuntary movement is an exercise that cannot normally be suppressed or can only be partially restrained [7]. Student 
becomes difficult to bend arbitrary movements arising temporarily in arms and hands. In that case, they may move their fingers to attract objects.

Intellectual disability is the state where the development of cognitive abilities has remained at a level where the cognitive ability development is generally delayed due to intellectual functional disorder that occurred until the developmental stage. The degree of intellectual impairment is shown below [8].

- Mild intellectual disability refers to intellectual disability with IQ generally 50-70. Meals, clothes removal, drainage etc. There is no hindrance to the everyday life skills of. But the development of language is slow, even 18 years old and above elementary school. It is often stayed at the raw level of academic ability.

- Medium intellectual disorder generally refers to intellectual disability with IQ of 35-50. Language development and delay in athletic ability. They can do yourself partly, but it is difficult to do everything.

- Severe intellectual disability refers to a mental disorder whose IQ is generally 20-35. Development of language and motor functions is slow. On the learning side, it is limited to reading and writing hiragana. The development of emotions is immature and one thing around us. Because it is difficult to do with people, protection and assistance may be necessary for food, clothing and shelter.

- Most severe intellectual disability refers to a mental disorder with an IQ of 20 or less. Words do not develop. It's almost time to stay screaming. They can handle all aspects of their life.

Mental rotation is a cognitive activity that rotates the visual stimulus presented in a rotated state mind and recognizes figures in an upright state without rotation [9].

Spatial recognition capability is the ability to quickly and accurately grasp and recognize the state and relationship of objects in 3D space such as position, orientation, attitude, size, shape and spacing of objects.

\section{B. Children in Concern}

Student A (Male) has a high intellectual level but it is difficult to express by speech language due to paralysis of upper and lower limbs. At school, he is sitting in a wheelchair. The physical condition of Student A can move his hands and arms with his own will and grips and opens his hands. When grasping objects, there is an influence of involuntary movements from one minute to five minutes. Legs are difficult to move by paralysis. Although there are physical restrictions due to paralysis of the upper and lower limbs in response to the instruction of the teacher, it is possible to speak "ah" "uh" or waving his own intention.

The range that Student A moves mainly by hand is shown in Fig. 1. Student A moves his face to see for those who are interested by judging who the ears are very good at the footsteps heard from the corridor. As an educational support for one year from 2015, we have been developing input devices to support Student A's intention display. Educational support from 2016 aims at improving the spatial recognition ability by learning to show intention by using Student A's own hand rather than listening, passive learning which is only viewing. Therefore, prepare two kinds of problems using building blocks and learn mental rotation.

Student B (Female) is difficult to express by speech language with the most severe intellectual disorder. Student B understands the daily movements such as correcting posture and instructions on learning using things, and acts as instructed. As a result of educational support so far, she can recognize plan figures and pictures. We tried to grasp the touch pen and select the same shape and picture as Fig. 2 using a tablet [10]. When we started educational support, we dropped or thrown tablet. However, with repeated support, we understand the content of the learning, and now we can correctly answer the problem more than a healthy person. Therefore, in this educational support, we will see what kind of response to the learning of the three-dimensional figure. We think that the ability to capture things in three dimensions in the future life is necessary and aim to improve mental rotation as well as Student A to improve space recognition ability.

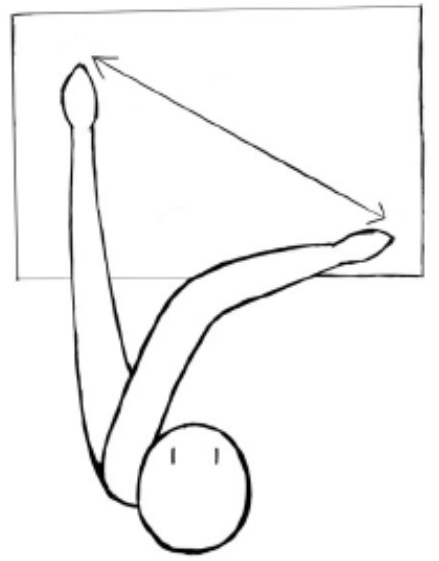

Fig. 1. Movable range of his / her hand.

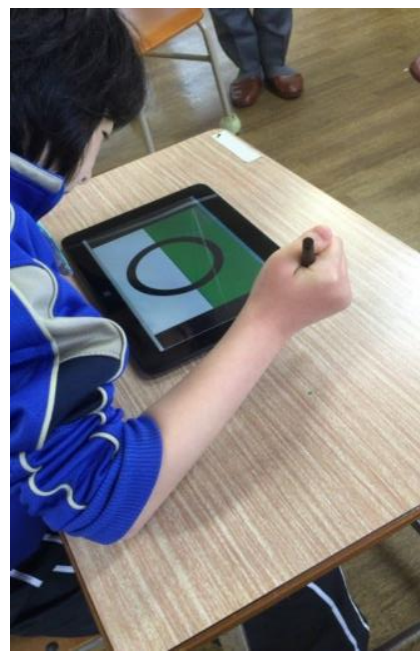

Fig. 2. Photo which shows character learning process. 


\section{EXPERIMENTS}

\section{A. Experimental Configuration}

In this section, we will describe the input device according to the target state described in Section 2. Touch pad that touches the copper plate to output signals and touch table to learn by touching the pen were prepared as input equipment considering the physical restriction due to the target obstruction.

Student A can wield his hand at his own will as described in 2.2. Therefore, we prepared a touch pad that outputs signals only by touching the hands. The touchpad is a mechanism that outputs signals (keys 1, 2, 3) by touching three copper plates. For this time, we are trying to learn by touching the upper left and lower right copper plates. Student A easily moves the hand to the upper left and the lower right, so the buttons are arranged accordingly. Understand the copper plate to understand that it corresponds to the learning material choice by sticking colored paper.

Student B used the tablet and the stylus used for educational support from three years ago. Student B sometimes drops things or throws things. Therefore, we use a tablet resistant to impact. In addition, because Student B is difficult to grab a thin pen, it made thick the touch pen so that it grips easily. The operation of the learning material can be learned by touching the option with the touch pen. Touchpad and tablet and touch pen are shown in Fig. 3 as building block learning tools.

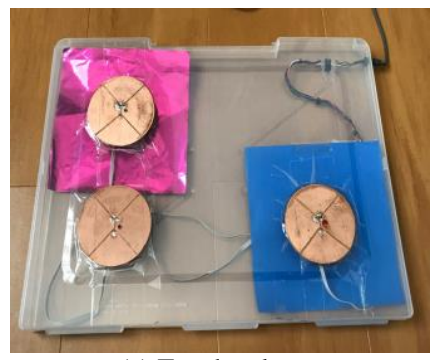

(a) Touchpad

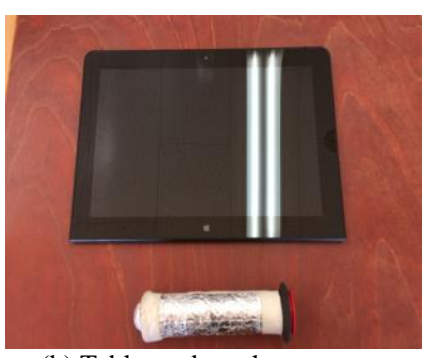

(b) Tablet and touch pen
Fig. 3. Building block learning tools (a) Alternately stab a sword

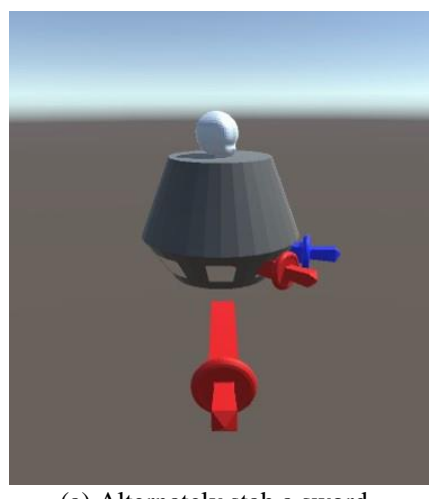

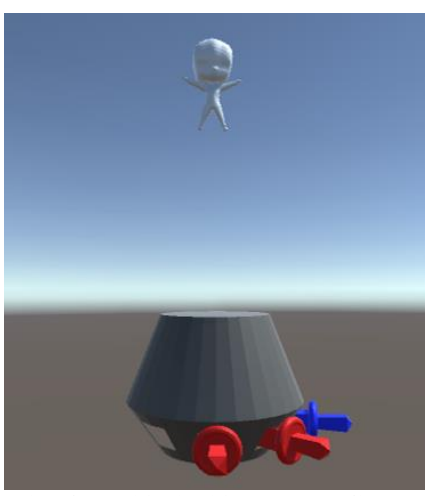

(b) If you hit the hit area you fly
Fig. 4. Toy model.

We describe the environment which we can play with 3DCG. For this time, learning is done with the teaching materials using 3DCG for the first time. Therefore, in order to give interest to 3DCG teaching materials which we have not seen so far, we have reproduced the familiar toys. By playing with the toy with that toy, we have not been able to play by myself, but by using this input device we can experience what we can operate and draw interest. After that, let's learn when the operation of the input device gets used.

Toy model reproduced the toy playing with teacher usually with 3DCG. Until now it was difficult to play with toys in hand by himself, but by using the input device according to the subject, they can operate their own toys and play. In the developed toy, they can "turn" the red of the touchpad by touching and touch the blue to "stab the sword" (Fig. 4). By touching the button on the tablet by displaying the button, the same action can be done.

We asked the special support school teacher to evaluate the developed toy model. Children who have difficulty playing with objects due to the obstacles this time are highly valued, such as wanting to try also by other students because they play very happily.

Children who have difficulty playing toys due to obstacles tend to give up a lot of things, becoming passive even if they are playful if their own thoughts do not pass. Therefore, it was found that the environment where the input device and the toy model can be combined and played as desired can be effective for children's active activities.

The building block play was reproduced on the PC (Fig. 5). The subjects A and B of this time let the students play with complicated operations but were not able to play, but had another obstacle. The student has never played with a building block because it is difficult to move down from the neck due to obstacles. Therefore, we prepared an environment where you can play building blocks on a PC. The student can move the mouse pointer using the line of sight input device. The operation method of this building block is to operate by performing the functions by hovering over the button displayed around the building block.

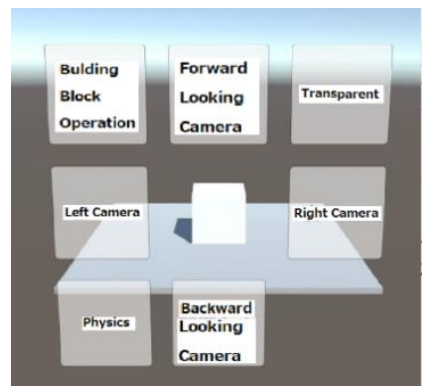

(a) Camera switch mode

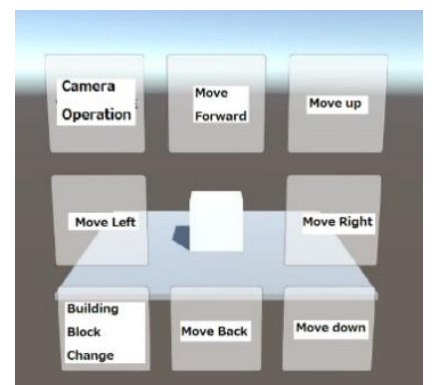

(b) Building block operation mode
Fig. 5. Building block toy model.

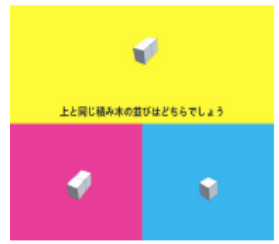

(a) Level 1

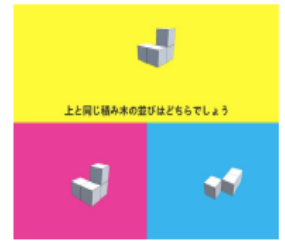

(b) Level 2

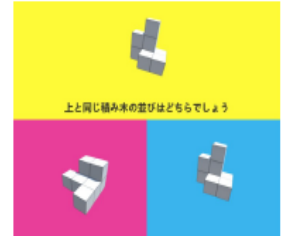

(c) Level 3
Fig. 6. Three difficulty level of building block toy model. 
The alignment teaching material of building blocks is a question concerning the arrangement of building blocks. Since the object understands the planar figure, it is a teaching material to check whether you understand the threedimensional shape before doing the building block problem. By rotating the arranged building blocks so that the whole is visible, we made it possible to see the viewpoint seen from the front and the viewpoint seen from behind. The question presentation (yellow frame) is placed on the screen and the options are arranged on the left and right (red frame, blue frame) under the screen. When presenting the question, rotate $360^{\circ}$ so that the whole can be seen and pause at every $180^{\circ}$ rotation. Three difficulty levels are set to change difficulty level, question number, number, and number of questions (Fig. 6).

This teaching material has become a teaching material to check whether the number of building blocks necessary to comprehend the shape of the arranged blocks and to compose the arranged shape can be counted. This teaching material also rotates so that the whole of the building blocks arranged in the same way as previously described model which is shown in Fig. 6. The number of remaining questions from this teaching material is displayed on the upper left of the screen as requested by the teacher (Fig. 7).

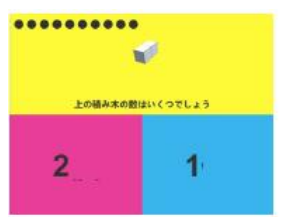

(a) Level 1

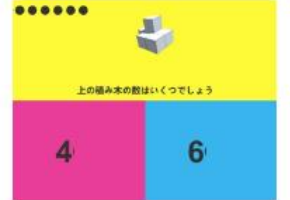

(b) Level 2

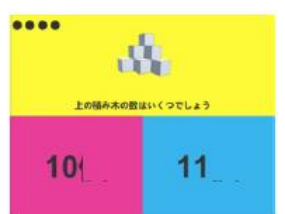

(c) Level 3
Fig. 7. Three difficulty level of block counting toy model.

In learning process flow, questions are presented when selecting the question number first (Fig. 8(a)). As soon as it is presented, options are displayed after the question sentence is read aloud. When answering, the question presentation section is inclined at the same angle as the selected building block, so that the difference between correct answer and incorrect answer can be understood (Fig. 8(b)).

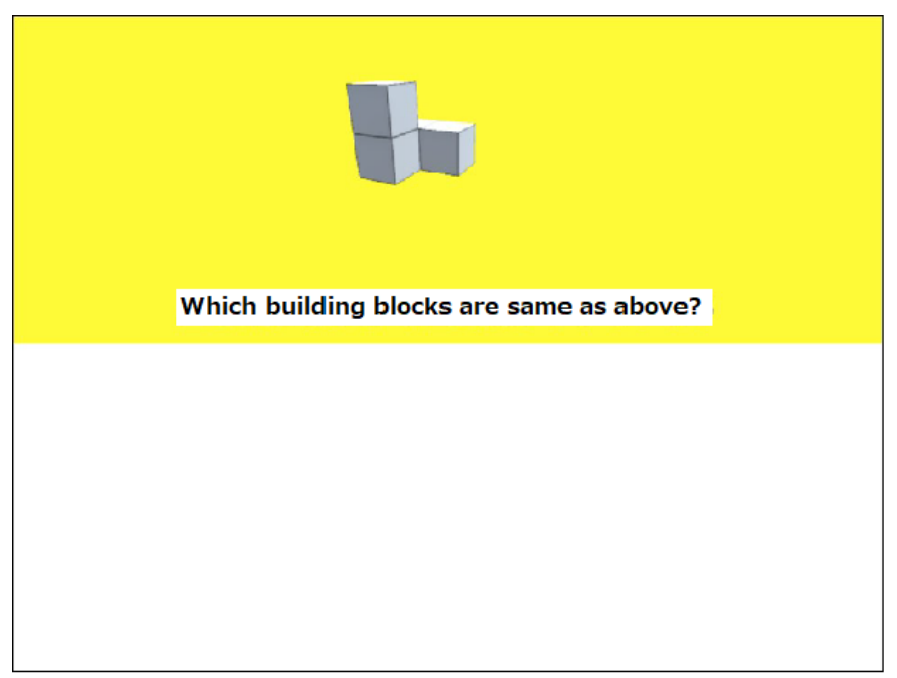

(a) Question
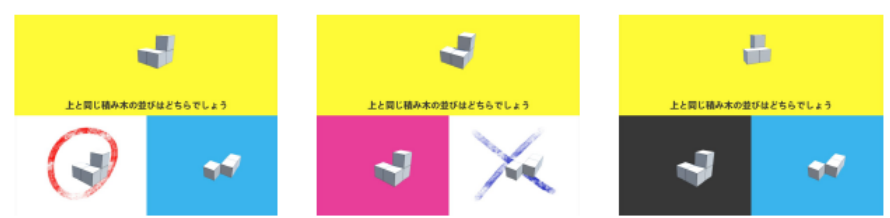

(b) Answer (Correct (left), Incorrect (middle), Mouse miss-operation

Fig. 8. Building block toy model.

The explanatory learning material is a teaching material for explaining the wrong answer after confirming whether the arrangement and number of building blocks are understandable. Choose the wrong answer with the learning materials, and the teacher draws a commentary with the viewpoint of the building blocks, the movement of the building blocks, and the building blocks drawing attention (Fig. 9). The operation procedure is shown below:

a) Move drag block while right clicking the block to move block.

b) Move drag view while left clicking on places other than building block to move view point.

c) Right click the block to change the color of the block.

d) Mouse wheel scaling to enlarge or shrink the block.

e) Click reset button to reset the position of the building block.

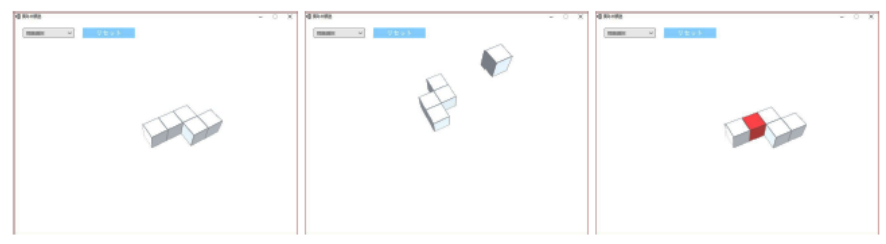

(a) Change the view point (b) Move the block (c) Look at the block

Fig. 9. Displaying the instructions.

The building block problem is a teaching material to answer the number of building blocks by performing mental rotation while imagining the arrangement of building blocks in the head from the viewpoint of the front, the upper, and the right from the viewpoint of the front side, the upper side, and the right side. This learns after learning the understanding of the shape of the building blocks and the number of building blocks with the learning materials of Fig. 10 (a) and 10 (b).

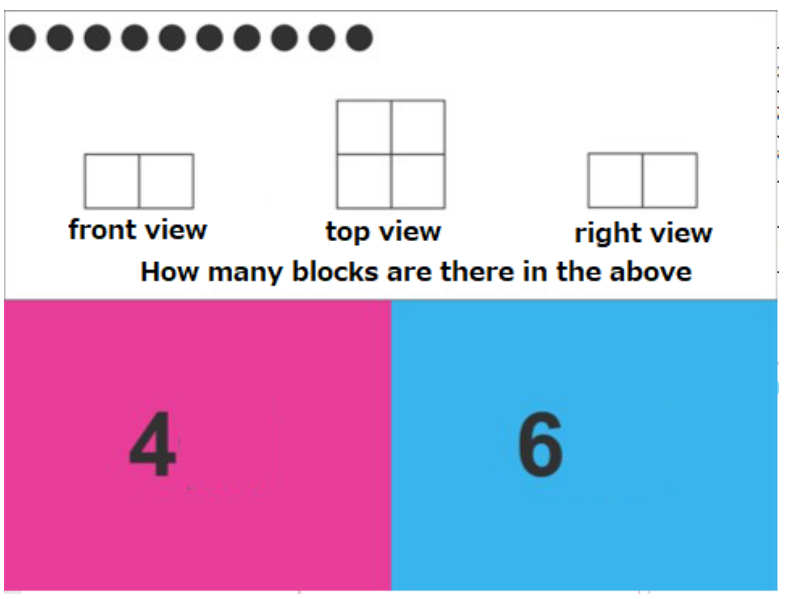

(a) Question No.1 


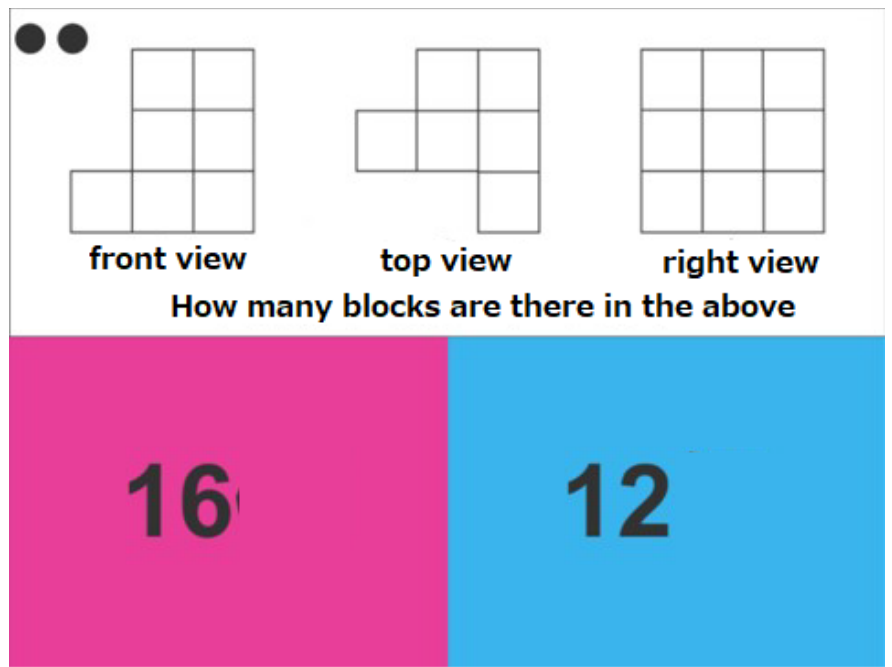

(b) Question No.2

Fig. 10. Building block questions.

In this question, let them answer the maximum number of blocks of blocks from the figure. By imagining from three viewpoints and grasping the position of the building blocks, it improves the space recognition ability. It is very good to be able to know the students' comprehension level as an evaluation by a special support school teacher. In school life, students have a lot of passive learning and students' intention is reflected in teaching materials, so that mistakes can be supplemented with commentary materials.

Even for Student A is difficult to touch the real building blocks, they can learn a lot through building teaching materials and it is very effective for learning. We would like to see students' reactions by letting other students learn using building blocks teaching materials. Very good evaluation was obtained from the target teacher this time.

We experimented to see if the shape of the building block was recognizable in three dimensions. Tables I and II as well as Fig. 11 show the results of making the blocking problem of the blocks.

A cross mark in the answer result is a case of an unintended answer or incorrect answer due to involuntary movements. When the score of Quiz 3 of the first learning and the score of Quiz 1 of the second learning were high, after seeing the screen for a while, they moved hands by hand and answered (average response time is 5 minutes).

TABLE I. SCORE AT THE First Time (StUdent A)

\begin{tabular}{|l|l|l|l|}
\hline Quiz1 & Ans. & Quiz 3. & Ans. \\
\hline 1 & $\circ$ & 1 & $\circ$ \\
\hline 2 & $\circ$ & 2 & $\mathrm{x}$ \\
\hline 3 & $\circ$ & 3 & $\mathrm{x}$ \\
\hline 4 & $\mathrm{x}$ & 4 & $\circ$ \\
\hline 5 & $\circ$ & 5 & $\circ$ \\
\hline 6 & $\circ$ & 6 & $\circ$ \\
\hline 7 & $\mathrm{x}$ & 7 & $\circ$ \\
\hline 8 & $\mathrm{x}$ & 8 & $\circ$ \\
\hline 9 & $\mathrm{x}$ & 9 & $\circ$ \\
\hline 10 & $\mathrm{x}$ & 10 & $\circ$ \\
\hline
\end{tabular}

TABLE II. SCORE AT THE SECOND TIME (STUDENT A)

\begin{tabular}{|l|l|l|l|}
\hline Quiz1 & Ans. & Quiz3 & Ans. \\
\hline 1 & $\circ$ & 1 & $\circ$ \\
\hline 2 & $\circ$ & 2 & $\mathrm{x}$ \\
\hline 3 & $\circ$ & 3 & $\circ$ \\
\hline 4 & $\circ$ & 4 & $\circ$ \\
\hline 5 & $\mathrm{x}$ & 5 & $\circ$ \\
\hline 6 & $\circ$ & 6 & $\mathrm{x}$ \\
\hline 7 & $\circ$ & 7 & $\circ$ \\
\hline 8 & $\circ$ & 8 & $\circ$ \\
\hline 9 & $\circ$ & 9 & $\circ$ \\
\hline 10 & $\circ$ & 10 & $\mathrm{x}$ \\
\hline
\end{tabular}

When Quiz 1's first learning score was low, they answered without looking at the screen (average response time is 24 seconds). For the wrong problem, the choice of correct answer and the choice of incorrect answer were relatively similar by one block difference. Since the score of learning when student A himself was concentrating was high, it was confirmed that he was firmly recognizing the shape of the building block.

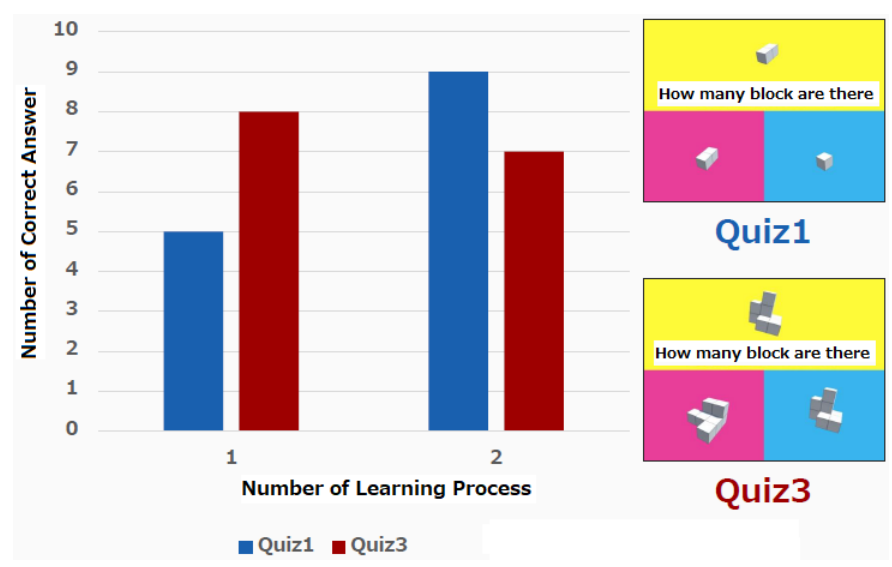

Fig. 11. Results of making the blocking problem of the blocks.

We experimented to see if we can count the number of building blocks that are lined up. Tables III to $\mathrm{V}$ as well as Fig. 12 show the results of counting the number of building blocks.

The score of Quiz 1 is high for the 1st and 2nd learning, but it is wrong with Question 8 (Fig. 13). What is considered as a cause is that since the problem is being rotated, it seems that the numbers are wrong because the front and rear shapes are similar.

TABLE III. SCORE AT THE First Time (StUdENT A)

\begin{tabular}{|l|l|l|l|}
\hline Quiz1 & Ans. & Quiz2 & Ans. \\
\hline 1 & $\bigcirc$ & 1 & $\mathrm{x}$ \\
\hline 2 & $\bigcirc$ & 2 & $\mathrm{x}$ \\
\hline 3 & $\bigcirc$ & 3 & $\mathrm{x}$ \\
\hline 4 & $\bigcirc$ & 4 & $\mathrm{x}$ \\
\hline 5 & $\bigcirc$ & 5 & $\mathrm{x}$ \\
\hline 6 & $\bigcirc$ & 6 & $\mathrm{x}$ \\
\hline 7 & $\bigcirc$ & 7 & $\bigcirc$ \\
\hline 8 & $\mathrm{x}$ & 8 & $\bigcirc$ \\
\hline 9 & $\bigcirc$ & 9 & $\mathrm{x}$ \\
\hline 10 & $\mathrm{O}$ & 10 & $\mathrm{x}$ \\
\hline
\end{tabular}


TABLE IV. SCORE AT THE SECOND Time (STUdENT A)

\begin{tabular}{|l|l|l|l|}
\hline Quiz1 & Ans. & Quiz2 & Ans. \\
\hline 1 & $\bigcirc$ & 1 & $\bigcirc$ \\
\hline 2 & $\bigcirc$ & 2 & $\mathrm{x}$ \\
\hline 3 & $\bigcirc$ & 3 & $\mathrm{x}$ \\
\hline 4 & $\bigcirc$ & 4 & $\mathrm{x}$ \\
\hline 5 & $\bigcirc$ & 5 & $\bigcirc$ \\
\hline 6 & $\bigcirc$ & 6 & $\mathrm{x}$ \\
\hline 7 & $\bigcirc$ & 7 & $\bigcirc$ \\
\hline 8 & $\mathrm{x}$ & 8 & $\bigcirc$ \\
\hline 9 & $\bigcirc$ & 9 & $\bigcirc$ \\
\hline 10 & $\bigcirc$ & 10 & $\bigcirc$ \\
\hline
\end{tabular}

TABLE V. SCORE AT THE THIRD Time (STUdENT A)

\begin{tabular}{|l|l|l|l|}
\hline Quiz1 & Ans. & Quiz2 & Ans. \\
\hline 1 & $\mathrm{x}$ & 1 & $\bigcirc$ \\
\hline 2 & $\mathrm{x}$ & 2 & $\mathrm{x}$ \\
\hline 3 & $\bigcirc$ & 3 & $\bigcirc$ \\
\hline 4 & $\mathrm{x}$ & 4 & $\bigcirc$ \\
\hline 5 & $\bigcirc$ & 5 & $\mathrm{x}$ \\
\hline 6 & $\mathrm{x}$ & 6 & $\bigcirc$ \\
\hline 7 & $\mathrm{x}$ & 7 & $\bigcirc$ \\
\hline 8 & $\bigcirc$ & 8 & $\mathrm{x}$ \\
\hline 9 & $\mathrm{x}$ & 9 & $\mathrm{x}$ \\
\hline 10 & $\mathrm{x}$ & 10 & $\bigcirc$ \\
\hline
\end{tabular}

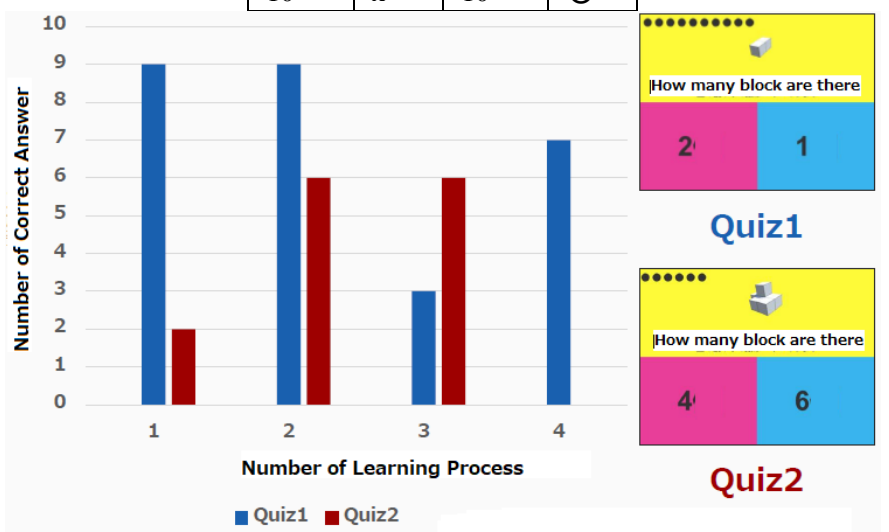

Fig. 12. Results of making the blocking problem of the blocks for Question 8.

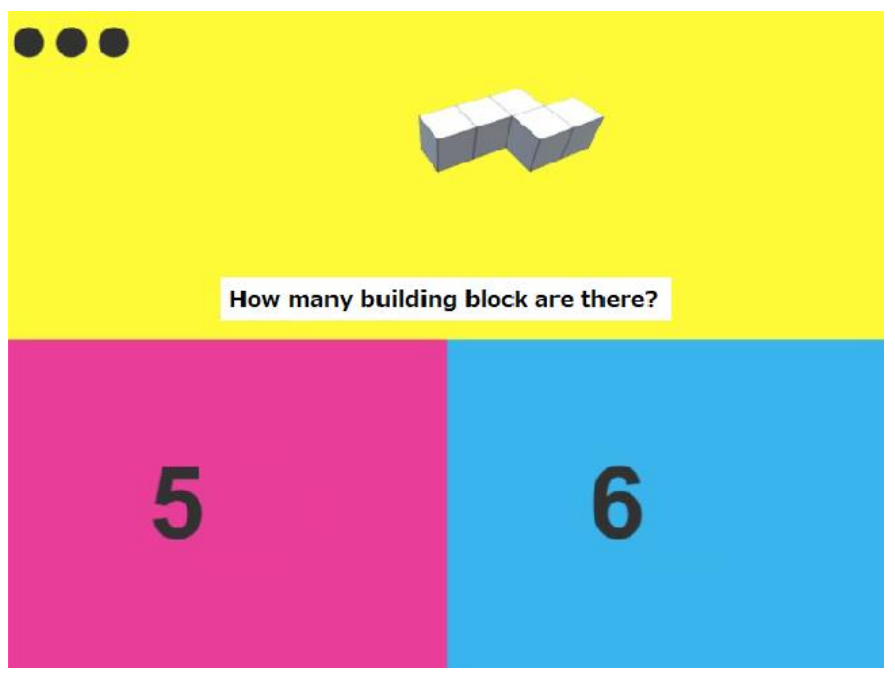

Fig. 13. Question No.8.
It seems to be because it judged that the number of building blocks before and after the problem presentation part and options are repeated while looking it repeatedly. Regarding Quiz 2, when three times of learning is repeated for the correct part, a high score is obtained. It was confirmed that the number of building blocks can be counted from the score.

Student A reacts sensitively to the sound, it is a level to judge who is just a footstep. He moves his face every time. He heard footsteps and tries to see it. Therefore, student A was enclosed in a partition and concentrated on the screen (Fig. 14). Until now, the teacher was supplemented (such as reading the position of the face and the problem) next to Student A, but Student A alone saw the screen and answered more. Furthermore, in order to draw motivation for learning, we changed the scenery at the time of learning for each question (Fig. 13). In the change of the landscape, although there was no influence on the score, time to see the screen and the input device increased, and it was possible to change the willingness to learn.

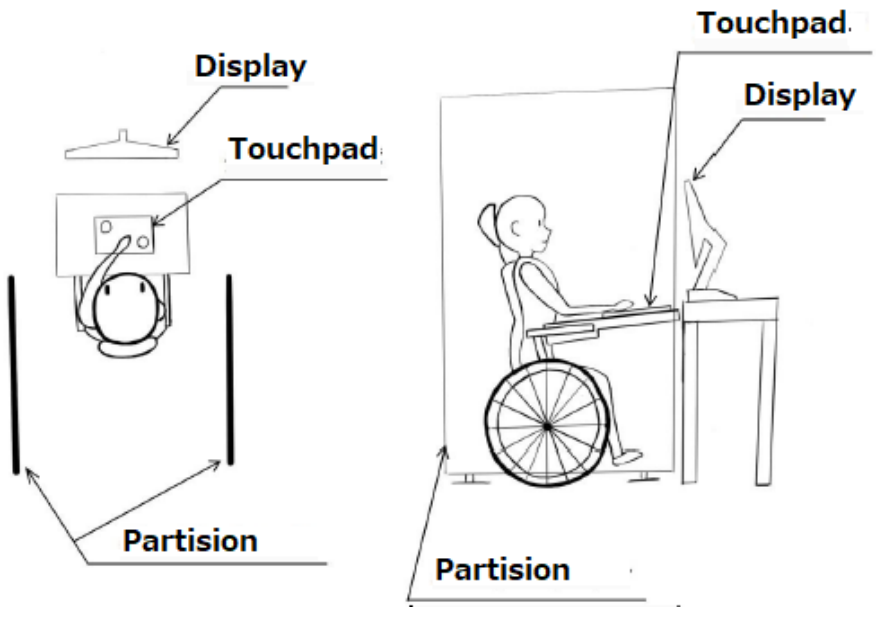

Fig. 14. Learning environment.

This section describes experiments on reactions of Student B to learning three-dimensional drawings. Student B knows that long-term learning is necessary from educational support so far to learning ability through learning. Therefore, we looked at what kind of response it would be to learning of a three-dimensional figure to work on for the first time. We got motivation for learning and examined the iterative learning till learning can be done just like educational support so far.

In addition to the educational support of plan figures and pictures so far, learning of building skill teaching materials of a three dimensional figure was done. Student B was unable to bring motivation for learning by dropping or throwing the tablet on the first teaching material. However, we were interested or had time to look at the rotating problem. From the teacher who saw this reaction, there was an opinion that the shape and the size did not change very much even if the plan view rotated, but it is difficult to rotate the threedimensional figure because the size and shape change.

\section{CONCLUSION}

In this research, improvement of spatial recognition ability and learning materials were effective for education for 
children with disabilities using educational materials using input devices and building blocks suitable for the target and educational support. It became possible for Student A to display their own intention rather than past passive learning. As a result, it was confirmed that Student A's positional relationship and spatial grasping ability are provided. Since the period of educational support was short, the measurement of space recognition ability due to the block trees problem was insufficient and we could not confirm the improvement of capacity.

Student B dropped or threw the teaching material for the first time for the teaching material to see, so learning effect was not seen. However, since we have to make repeated learning for a long period of time from educational support so far, we will measure the learning effect by looking at the future response. Overall, we could not measure the learning effect from the learning and the score using the teaching materials, but in terms of providing a learning environment tailored to each individual disability, we highly evaluated from the faculty and tried it for other students, I was able to know that it was effective as well.

As a future task, it is difficult to learn using only input devices and learning materials. Differences appear in the ability to concentrate due to the sound and scenery at learning, and it is influenced by the learning score. In the future, it is a task to measure the learning effect by long-term educational support while considering not only the object but also surrounding environment.

\section{ACKNOWLEDGMENTS}

Author would like to thank the participants (Student A and B) of the experiment.

\section{REFERENCES}

[1] Ito Tomisato, Takahashi Toshiyuki: Various developmental features seen in building blocks of an infant, Journal of Art Education Society, 32 (0), pp 41-53, 2011.

[2] Special education school guidelines for teaching, etc., high 1,2009.

[3] Kotaro Taguchi, Mariko Oda, Hiroshi Kouno Seio Oda, Kohei Arai, Development of learning support software with CG animations for intellectually disabled children, Journal of Education System and Information Society of Japan, 30,1, 48-56, 2014

[4] Kohei Arai, Taiki Ishigaki, Mariko Oda, Spatial comprehension exercise system with 3D CG of toy model for disable children, IJACSA, 8, 4, 189-194, 2017.

[5] Taiki Ishigaki, Mariko Oda, Kohei Arai, Learning content for improvement of spatila comprehension capability with 3D CG toy model for disable children, Proceedings of the 3rd ADADA Conference of the Asian Society of Digital Art and Design, at the Kurume Institude Technology, 2017.

[6] Social Welfare Corporation Japan Association for Handicapped Children http://nishikyo.or.jp/about_us/index.html (Accessed on June 21 2018)

[7] Kaori Dragon: Examination of involuntary movements, clinical neurophysiology, vol. 43, No. 4, pp. 122-141, 2015.

[8] Developmental navigation https://h-navi.jp/column/article/73 (Accessed on June 212018 )

[9] Information dissemination for therapists http://journals.plos.org/plosone/article?id=10.1371/journal.pone.018098 5; http://www.comp.tmu.ac.jp/locomotion-lab/higuchi/higu-therapistold17.html (Accessed on June 21 2018)

[10] Moriko Oda, Seio Oda, Hiroshi Kono, Hideto Sazuka, Masahito Takahashi: Engineering and Educational Support for Regional Special Support Schools by Service Learning, Research Report on Educational System Information Society, vol. 29, No. 6, pp 115- 120, 2015.

\section{AUTHOR's PROFILE}

Kohei Arai, He received BS, MS and PhD degrees in 1972, 1974 and 1982, respectively. He was with The Institute for Industrial Science and Technology of the University of Tokyo from April 1974 to December 1978 also was with National Space Development Agency of Japan from January, 1979 to March, 1990. During from 1985 to 1987, he was with Canada Centre for Remote Sensing as a Post-Doctoral Fellow of National Science and Engineering Research Council of Canada. He moved to Saga University as a Professor in Department of Information Science on April 1990. He was a counselor for the Aeronautics and Space related to the Technology Committee of the Ministry of Science and Technology during from 1998 to 2000 . He was a councilor of Saga University for 2002 and 2003. He also was an executive councilor for the Remote Sensing Society of Japan for 2003 to 2005 . He is an Adjunct Professor of University of Arizona, USA since 1998. He also is Vice Chairman of the Science Commission "A" of ICSU/COSPAR since 2008 then he is now award committee member of ICSU/COSPAR. He wrote 37 books and published 570 journal papers. He received 30 of awards including ICSU/COSPAR Vikram Sarabhai Medal in 2016, and Science award of Ministry of Mister of Education of Japan in 2015. He is now Editor-in-Chief of IJACSA and IJISA. http://teagis.ip.is.saga-u.ac.jp/index.ht 